\title{
Methotrexate Regimen
}

National Cancer Institute

\section{Source}

National Cancer Institute. Methotrexate Regimen. NCI Thesaurus. Code C160085.

A chemotherapy regimen consisting of methotrexate that may be used in the treatment of bladder, and head and neck cancers. 